\title{
The Clinical Impact of Low Doses of Dasatinib in Patients with Chronic Myeloid Leukemia
}

\author{
Salih AKSU', Fahri SAHIN², Burak UZ ${ }^{1}$, Selim A. YAVUZ ${ }^{3}$, Hilmi ATAY ${ }^{4}$, Engin KELKITLI ${ }^{4}$, \\ Mehmet TURGUT ${ }^{4}$, Mustafa PEHLIVAN ${ }^{5}$, Meltem O. AKAY ${ }^{6}$, Emel GURKAN ${ }^{7}$, Muzaffer DEMIR ${ }^{8}$, \\ Selda KAHRAMAN ${ }^{9}$, Fatih DEMIRKAN ${ }^{9}$, Semra PAYDAS ${ }^{7}$, Güray SAYDAM ${ }^{2}$, \\ Ibrahim C. HAZNEDAROGLU ${ }^{1}$ \\ ${ }^{1}$ Hacettepe University Faculty of Medicine, Department of Hematology, Ankara \\ ${ }^{2}$ Ege University, Faculty of Medicine, Department of Hematology, Izmir \\ ${ }^{3}$ Istanbul University, Faculty of Medicine, Department of Hematology, Istanbul \\ ${ }^{4}$ Ondokuz Mayis University, Faculty of Medicine, Department of Hematology, Samsun \\ ${ }^{5}$ Gaziantep University Faculty of Medicine, Department of Hematology, Gaziantep \\ ${ }^{6}$ Osmangazi University, Faculty of Medicine, Department of Hematology, Eskisehir \\ ${ }^{7}$ Cukurova University, Faculty of Medicine, Department of Hematology, Adana \\ ${ }^{8}$ Trakya University, Faculty of Medicine, Department of Hematology, Edirne \\ ${ }^{9}$ Dokuz Eylül University, Faculty of Medicine, Department of Hematology, Izmir, TURKEY
}

\begin{abstract}
We report our experience in 41 patients with chronic phase (CF)-chronic myeloid leukemia (CML) who had discontinued imatinib switched to dasatinib, retrospectively. The CF-CML patients received dasatinib at starting dose of 100 once daily. Dose adjustment were observed in 11 patients, respectively. In case of other circumstances, treatment has been continued with a lower dose if needed. The median dose of dasatinib was $100 \mathrm{mg}$ daily (range: 50 to $140 \mathrm{mg}$ ). We conclude that even lowdose dasatinib therapy is an effective and safe in second line treatment of CML patients patients.
\end{abstract}

Keywords: Chronic myeloid leukemia, Dasatinib, Treatment dosage

ÖZET

Kronik Myelositer Lösemi Tedavisinde Düşük Doz Dasatinib'in Klinik Etkinliği

Imatinib tedavisinden ayrlan kronik faz kronik miyeloid lösemi tanısı alan ve dasatinib tedavisine geçen 41 tam yanıt॥ olduğu bilinen ve son 1 yıldır aylık olarak aldığı dozları bilinen hastada restrospektif olarak bir yıl süresince hastaların ortalama dasatinib dozları araştırıdı. Bu hastaların hepsinde dasatinib tedavi başlangıç dozu 100 mg/gün idi. Onbir hastada doz ayarlanması yapıldığı gözlendi. Çeşitli nedenlerden dolayı, intiyaç olunduğunda tedaviye daha düşük bir dasatinib dozu ile devam edildiği gözlenmiştir. Medyan dasatinib dozu 100 mg idi (aralık: 50-140 mg). Sonuç olarak, düşük doz dasatinib bile KML hastalarının ikinci basamak tedavisinde hastalarda etkin ve güvenilir bir tedavi seçeneğidir.

Anahtar Kelimeler: Kronik miyeloid lösemi, Dasatinib, Tedavi dozlaması 


\section{INTRODUCTION}

Chronic myeloid leukemia (CML), a clonal myeloproliferative disorder of blood stem cells ${ }^{1}$, has been caused by a genetic abnormality which is the breakpoint cluster gene between chromosomes 9 and 22. ${ }^{2}$ Tyrosine kinase inhibitors (TKIs) including imatinib, dasatinib and nilotinib which have created the oppotunity for tailored CML treatment and if eligible stem cell transplantation (SCT) are current treatment options for CML. $\cdot^{3.5}$ In Turkey, the current standart first-line therapy for patients with newly-diagnosed chronic phase-CML is imatinib. Dasatinib and nilotinib have still been using in clinical practice to manage the treatment of CML patients who had resistance and intolerant to imatinib. Thus, TKIs are essential for the treatment of CML disease and it's continuity is also crucial.

The patients with CML frequently need transient treatment interruptions and dose reductions during their treatment with 2nd-generation TKIs due to adverse events, ${ }^{6-9}$ patient's compliance problems..$^{10-12}$ Dasatinib (Sprycel;N-(2-Chloro-6-methylphenyl)2-[[6-[4-(2-hydroxyethyl)-1-piperazinyl]-2methyl-4-pyrimidinyl]amino]-5-thiazolecarboxamide monohydrate, Bristol-Myers Squibb) is a potent, orally ABL kinase in-hibitor and binds to both the active and also inactive con-formation of the ABL kinase domain. ${ }^{13}$ Nilotinib (Tasigna; N-[3-[3(1H-imidazolyl)propoxy] phenyl]-4-methyl-3-[[4(3-pyridinyl)-2-pyrimidinyl]amino] benzamide; Novartis Pharmaceuticals), a novel orally bioavailable derivative of imatinib, is a tyrosine kinase inhibitor with improved target specificity. ${ }^{14,15}$ Like imatinib, nilotinib inhibits Bcr-Abl by binding to only an inactive conformation of the ABL kinase domain. $^{16}$

Low adherence to long-term maintenance therapy is a known challenge in a number of chronic diseases. Adherence among patients with chronic diseases averages only $50 \% .{ }^{17}$ In CML, one study indicated that $51 \%$ of the patients take $<85 \%$ of their prescribed dose within the first year of their treatment. ${ }^{10}$ The correlation between poor adherence to imatinib and clinical outcomes including poor response rates, high loss of response rates has been previously demonstrated among CML patients in clinical study settings. ${ }^{11,18}$ Yood et al showed that in the patients who received nilotinib as a 2nd-line tre- atment, adherence problems have been reported almost two times more compared with dasatinib $\leq$ $100 \mathrm{mg} /$ day. 10 Age, sex, number of concomitant medications, number and type of comobidities, dosing schedule (e.g. once vs twice/ day), dosing restrictions (e.g. taking with / without food), and/or number intensity of adverse events could influence patients adherence. ${ }^{10}$

Treatment complexity is another factor that may affect adherence to BCR-ABL inhibitors. To decrease the risk of gastrointestinal irritation, imatinib doses should be taken with a meal and a large glass of water and the dose of imatinib $400 \mathrm{mg} /$ day. ${ }^{19}$ The recommended daily dose of nilotinib $(800 \mathrm{mg} /$ day) requires twice-daily dosing and doses should be taken $\sim 12$ hours apart. Because of the following, no food should be consumed 2 hours before and 1 hour after each nilotinib dose. ${ }^{20}$ However, the recommended daily dose of dasatinib (100 mg/day) can be taken in a single dose without fasting and with or without a meal..$^{21}$ In case of severe AEs, reduced dose of imatinib, nilotinib and dasatinib are 300 , 400 and $80 \mathrm{mg} /$ day. ${ }^{19-21}$ However, dasatinib has a rich diversity of tablet formulation like 20,50, 70, $80,100 \mathrm{mg}$. Thus, it is the only tyrosine kinase intihibitor which has adjustable dose application.

The use of lower dose of TKIs may be resulted in reduced efficacy of therapy. There are several studies in order to clarify this correlation when using imatinib for patients with CML. Sneed et al. has stated that the patients who have received lower dose of imatinib have a worse cytogenetic response rate. ${ }^{22}$ In addition, the higher initial imatinib doses may cause the better response rates, and more adverse events. ${ }^{23-25}$

The incidences of my-elosuppression and pleural effusion were significantly lower with dasatinib $100 \mathrm{mg}$ daily compared with dasatinib at $70 \mathrm{mg}$ twice daily. ${ }^{26}$ Close monitoring and timely intervention are necessary for patients at risk for developing pleural effusions. One study showed that in patients with CML who are resistant or intolerant to imatinib, lymphocytosis has been reported during dasatinib treatment and has been associated with increased incidence of pleural effusion. ${ }^{27}$ Cytogenetic response rates to dasatinib were presented as higher in the group of patients with pleural effusion. ${ }^{26,28}$ DASISION study has also indicated the similar results. ${ }^{29}$ 
Table 1. Demographic characteristics of the patients

$$
\text { Variable }
$$$$
\text { n: } 41
$$

Age: Mean \pm Std. Deviation (year)

Gender: Women (\%)

Visani et al. demonstrated that dasatinib, even at low doses, induces and maintains responses (cytogenetic, hematologic and molecular) in real-life CML patients who were resistant and/ or intolerant to imatinib treatment. ${ }^{26}$ In addition, the "weekend drug holiday" in patients who developed pleural effusion during dasatinib treatment, a reduced schedule (3-5 days on and 4/2 days off), showed the same efficacy. ${ }^{27}$ In this study, we thus analysed the significance of dose reductions and treatment interruptions among patients treated with dasatinib.

\section{MATERIALS, METHODS AND RESULTS}

Forthy-one patients who have not entered blastic or accelerated phase in the last year and using dasatinib for at least one year, registered to the CML enrollment study between the dates 24.07.2007 and 13.03.2012 with known dosages of their medication on a monthly basis and who are CML patients with "Complete" response and in chronic phase for the last year meet these criteria among the 132 CML patients treated by dasatinib at nine universities which are located in Turkey. Dasatinib doses that were taken in the last 12 months starting from the last records, patient age and gender, reason of the change in dose if exists, dasatinib initiation dose, reason to switch to the second level TKI, last dose of the imatinib, and if the mutation analysis exists or not were identified in the database. Mean dasatinib dose of these patients, monthly and in the last year and mean drug costs monthly and yearly were calculated from the refunding foundation point of view. Effect of the clinical and demographic factors found in this database to the decrease in the dosage was assessed. Mean drug costs were calculated by calculating the mean of the monthly used medications that correspond to each patient's 12 months medication dose. Monthly collected daily dosage data were calculated for each patient one by

\begin{tabular}{|ll|}
\hline \multicolumn{2}{|l|}{$\begin{array}{l}\text { Table 2. Mean dosage of the patients regarding the } \\
\text { months. }\end{array}$} \\
\hline Month & Mean dosage \pm Std. Deviation \\
\hline 1 & $92 \pm 23$ \\
2 & $91 \pm 24$ \\
3 & $91 \pm 24$ \\
4 & $91 \pm 24$ \\
5 & $93 \pm 19$ \\
6 & $92 \pm 20$ \\
7 & $93 \pm 18$ \\
8 & $94 \pm 20$ \\
9 & $90 \pm 22$ \\
10 & $93 \pm 19$ \\
11 & $89 \pm 27$ \\
12 & $90 \pm 25$ \\
\end{tabular}

one and mean cost was calculated with respect to the Social Security Institution point of view including a month corresponds to a day. SPSS for Windows version 17 was used in all of the analysis. Demographic information of the patients are presented in Table 1. Average age is 50 and $46.3 \%$ of the patients are women.

Mean dosage of the patients regarding the months are presented in Table 2. While the mean dosage was 92 in the first month, this mean was observed as 90 in the last month.

The line graph regarding the mean dasatinib dosages patients were using was presented below (Figure 1). It can be observed from the graph that the used dasatinib dosage is presenting a decreasing trend.

The frequencies of the reasons of the changes in doses are reported as $11(26.8 \%)$ patients with change in doses. Mean dasatinib is $92 \mathrm{mg}$ that the patients were initially using. Patients were observed to use minimum $40 \mathrm{mg}$, maximum $140 \mathrm{mg}$ dasatinib at the study initiation (Table 3).

The reason of the patients' switching to the second lineTKI are presented in Table $4.80 .4 \%$ of the patients were observed to switch to the second line TKI because of inefficacy, $7.3 \%$ of them switched 


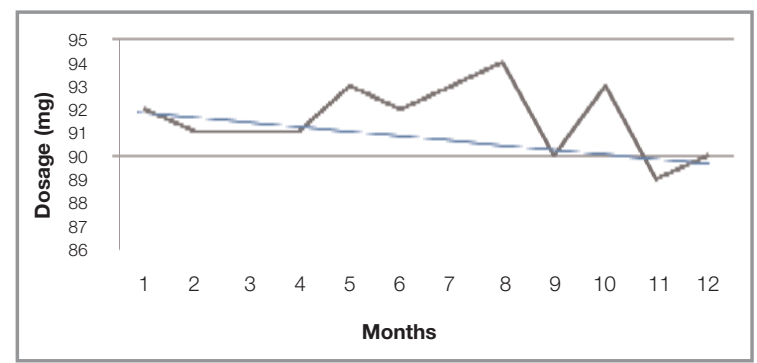

Figure 1. The mean dose of patients by month

because of no response, $9.8 \%$ of them switched because of intolerance problem and adverse effects.

Descriptive statistics regarding the last imatinib dosages that were used by the patients were presented in Table 5. Mean dose of imatinib that the patients last used is $486 \mathrm{mg}$. The imatinib dosage that were lastly used by the patients were minimum $300 \mathrm{mg}$ and maximum $800 \mathrm{mg}$.

It is observed that mutation analysis was performed in $43.9 \%$ of the patients and was not performed in $56.1 \%$ of the patients that were enrolled to the study (Table 6).

Average dosage cost per month is presented in Table 7. While the dosage cost of the patients were 153 TL initially, it was observed to be approximately $148 \mathrm{TL}$ in the last month of study. On this respect, we can claim that monthly costs decrease with the dose reduction and daily costs are reduced down to $148 \mathrm{TL}$ in patients that are stable or complete response. Annual average cost is $152 \pm 3 \mathrm{TL}$. This explains providing the cheapest treatment choice in the 2nd level in chronic CML treatment.

The reduction in average dose cost of patients are presented in Figure 2.

Table 5. Imatinib last usage dosage, mg/day

\begin{tabular}{ll}
\hline Statistics & \\
Mean \pm Std. Deviation, mg/day & $486 \pm 147$ \\
Minimum & 300 \\
Maximum & 800
\end{tabular}

Table 3. Dasatinib initiation dose, mg/day

\section{Statistics}

Mean \pm Std. Deviation, mg/ day $92 \pm 23$

Minimum 40

Maximum 140

Table 4. Reasons to switch to the second line TKI

Reason

f (\%)

Inefficacy, secondary resistance

No response, primary resistance

Tolerance problem regarding AEs

Other

\section{DISCUSSION}

The introduction of the imatinib has suprisingly improved the survival time for patients with CML. However, upon resistance or intolerance to imatinib, appropriate therapeutic modifications are required. Use of second-line therapy with dasatinib or nilotinib may overcome imatinib resistance or intolerance. ${ }^{8}$ Dasatinib has allowed a shift in the treatment of patients with CML, across all phase of disease, who develop resistance or intolerance to imatinib in Turkey. A retrospective study has been designed to understand CML patients treated with dasatinib as second-line therapy reflecting the realworld clinical practice. A total of 41 patients from different universities in Turkey satisfied the selection criteria and were included in the analysis. The main reason of the switch from imatinib (80.4\%) has been reported as secondary resistance. It is very well-known that the patients with CML require do-

Table 6. Mutation analysis of the patients

\section{f (\%)}

Existent

$18(43.9 \%)$

Nonexistent

$23(56.1 \%)$
$33(80.4 \%)$

$3(7.3 \%)$

$4(9.8 \%)$

$1(2.4 \%)$

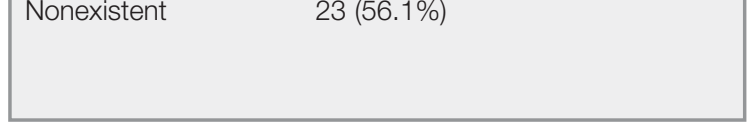




\begin{tabular}{|ll|}
\hline \multicolumn{2}{|l|}{ Table 7. Average Dosage Costs Of Patients Per Months } \\
\hline Month & Average dosage cost (TL) \\
\hline 1 & 153 \\
2 & 152 \\
3 & 152 \\
4 & 152 \\
5 & 155 \\
6 & 153 \\
7 & 155 \\
8 & 155 \\
9 & 150 \\
10 & 155 \\
11 & 147 \\
12 & 148 \\
\hline
\end{tabular}

se reductions during the TKI treatment. ${ }^{6-9,10-12}$ The median actual daily dose for patients with CML-CP during the START-C and START-R trials was close to $100 \mathrm{mg}$ (101 $\mathrm{mg}$ and $103 \mathrm{mg}$, respectively). ${ }^{30,31}$ However, in this study, mean dasatinib dosage was $92 \mathrm{mg} /$ day in the first-month and $90 \mathrm{mg} /$ day in the last month of the treatment (range; $40-140 \mathrm{mg} / \mathrm{day}$ ).

We have previously published the overview of the Turkish CML/ $\mathrm{Ph}^{(+)}$ALL patients treated with dasatinib under the compassionate use program before registration of dasatinib in Turkey. ${ }^{33}$ In this analysis, we have evaluated 114 patients in terms of switching reason from imatinib, the disease status at the switching time, the dosing schedule and adverse events under dasatinib treatment. Unfortunately, because of the heterogeneity of the group, it was not possible to analyze dose regimen, but subgroup analyses have revealed that certain number of patients have been treated with lower doses even ranged from 20 to $40 \mathrm{mg}$ dasatinib per day with long term efficacy and safety and acceptable response rates (unpublished data). Although, under the information provided by current international guidelines, all the patients with chronic phase CML who needed to switch their therapies to dasatinib from imatinib should be treated with $100 \mathrm{mg}$ QD dasatinib, because of the severe side effects like

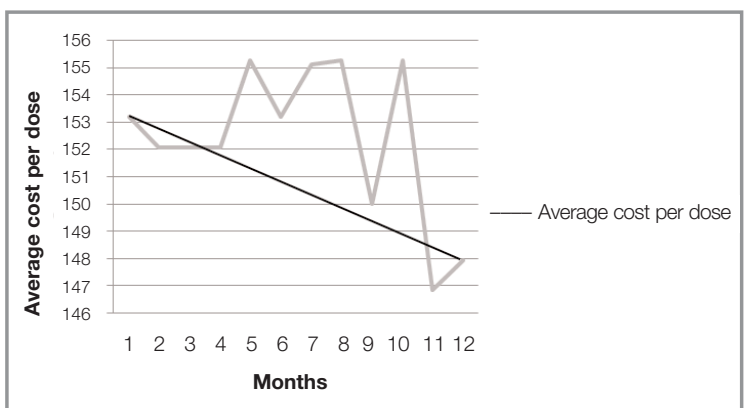

Figure 1. Average cost per dose

pleural effusion, it is needed to restart with lower doses of dasatinib in certain cases and then to increase to targeted dose of dasatinib. ${ }^{34}$ This article provided the rationale that in these cases, the patients have been treated appropriately even with lower doses of dasatinib for relatively longer periods without any doubt for progression risk.

In recently published reviews by Buyukasik et al., it was summarized the last decade history of CML regarding the amazing developments of therapeutic side of the disease including TKI's and understanding the molecular background for this development. ${ }^{35,36}$ In this review articles, it was briefly mentioned about the potential dose variations of dasatinib in different type of patients and and in different clinical situations with acceptable efficacy and safety.

There have been many reports showing the potential effectiveness of different dosage regimens for dasatinib which could potentiate the individualized therapy based on the patient's characteristics and comorbodities even facilitating the use of desired drug without changing the drug for the physicians. ${ }^{37,38}$

This study underlined the real-world clinical and economic outcomes associated with the use of dasatinib. Dasatinib has a wide tablet formulations like 20,50, $70 \mathrm{mg}$ in Turkey and thus can provides an adjustable dose application. Even at low doses of dasatinib are associated with higher response rates in Turkish patients with CML. While further studies are warranted, this research provides clinical and economic evidences to help clinicians and healthcare administrators in selecting second-line treatment for CML patients resistant or intolerant to imatinib. 


\section{REFERENCES}

1. Kantarjian HM, Talpaz M, Giles F, O'Brien S, Cortes J. New insights into the pathophysiology of chronic myeloid leukemia and imatinib resistance. Ann Intern Med 145: 913-923, 2006.

2. Faderl S, Talpaz M, Estrov Z, O'Brien S, Kurzrock R, Kantarjian HM. The biology of chronic myeloid leukemia. N Engl J Med 341:164-172, 1999.

3. National Comprehensive Cancer Network Clinical Practice Guidelines in Oncology. Chronic Myelogenous Leukemia v2.2009. http://www.nccn.org/ professionals/physician_gls/PDF/cml.pdf. Accessed February 9, 2009.

4. Baccarani M, Saglio G, Goldman J, et al. Evolving concepts in the management of chronic myeloid leukemia: recommendations from an expert panel on behalf of the European LeukemiaNet. Blood 108: 1809-1820, 2006.

5. Giralt SA, Arora M, Goldman JM, et al. Impact of imatinib therapy on the use of allogeneic haematopoietic progenitor cell transplantation for the treatment of chronic myeloid leukaemia. Br J Haematol 137: 461467, 2007.

6. Cortes J, Kim DW, Raffoux E, et al. Efficacy and safety of dasatinib in imatinib-resistant or -intolerant patients with chronic myeloid leukemia in blast phase. Leukemia 22: 2176-2183, 2008.

7. Hochhaus A, Baccarani M, Deininger M, et al. Dasatinib induces durable cytogenetic responses in patients with chronic myelogenous leukemia in chronic phase with resistance or intolerance to imatinib. Leukemia 22: 1200-1206, 2008.

8. Kantarjian HM, Giles F, Gattermann N, et al. (2007) Nilotinib (formerly AMN107), a highly selective BCR-ABL tyrosine kinase inhibitor, is effective in patients with Philadelphia chromosomepositive chronic myelogenous leukemia in chronic phase following imatinib resistance and intolerance. Blood 110: 3540-3546, 2007.

9. le Coutre, P., Ottmann, O.G., Giles, F., et al. Nilotinib (formerly AMN107), a highly selective BCR-ABL tyrosine kinase inhibitor, is active in patients with imatinibresistant or -intolerant accelerated-phase chronic myelogenous leukemia. Blood 111: 1834-1839, 2008.

10. Yood MU, Oliveria SA, Hirji I, et al. Adherence to treatment in patients with chronic myelogenous leukemia during a 10-year time period: A medical record review, 52. American Society of Hematology Annual Meeting, Orlando, FL.December 4-7, 2010; A1235.

11. Noens L, van Lierde M-A, De Bock R, et al. Prevalence, determinants, and outcomes of nonadherence to imatinib therapy in patients with chronic myeloid leukemia: the ADAGIO study. Blood 113: 5401-5411, 2009.

12. Marin D, Bazeos A, Mahon F-X, et al. Adherence is the critical factor for achieving molecular responses in patients with chronic myeloid leukemia who achieve complete cytogenetic responses on imatinib. J Clin Oncol 28: 2381-2388, 2010.
13. Shah NP, Tran C, Lee FY, et al. Overriding imatinib resistance with a novel $A B L$ kinase inhibitor. Science 305: 399-401, 2004.

14. Weisberg E, Manley PW, Breitenstein W, et al . Characterization of $\mathrm{AMN107}$, a selective inhibitor of native and mutant Bcr-Abl. Cancer Cell 7: 129-141, 2005.

15. Golemovic M, Verstovsek S, Giles F, et al. AMN107, a novel aminopyrimidine inhibitor of BCR-ABL, has in vitro activity against imatinib-resistant chronic myeloid leukemia. Clin Cancer Res 11: 4941-4947, 2005.

16. Manley PW, Cowan-Jacob SW, Fendrich G, et al. BcrAbl binding modes of dasatinib, imatinib and nilotinib: an NMR study, 48. American Society of Hematology Annual Meeting, Orlando, FL, December 9-12, 2006: P108.

17. WHO Pub Full Report 2003. http://www.who.int/chp/ knowledge/publications/adherence_full_report.pdf. Accessed October 13, 2010.

18. DarkowT, HenkH, Thomas S, et al. Treatment interruptions and non-adherence with imatiniband associated healthcare costs: a retrospective analysis among managed care patients with chronic myelogenousleukaemia. Pharmacoeconomics 25: 481-496, 2007.

19. Gleevec® (imatinib) SmPC. Novartis.

20. Tasigna $\AA$ (nilotinib) SmPC. Novartis.

21. SPRYCEL® (dasatinib) SmPC. Bristol-Myers Squibb.

22. Sneed TB, Kantarjian HM, Talpaz M, et al. The significance of myelosuppression during therapy with imatinib mesylate in patients with chronic myelogenous leukemia in chronic phase. Cancer 100: 116-121, 2004.

23. Kantarjian H, Talpaz M, O'Brien S, et al. High-dose imatinib mesylate therapyin newly diagnosed Philadelphia chromosome-positive chronic phase chronic myeloid leukemia. Blood 103: 2873-2878, 2004.

24. Hughes TP, Branford S, White DL, et al. Impact of early dose intensity on cytogenetic and molecular responses in chronic- phase CML patients receiving 600 mg/day of imatinib as initial therapy. Blood 112: 39653973, 2008.

25. Cortes J, Baccarani M, Guilhot F, et al. A Phase III, randomized, openlabel study of $400 \mathrm{mg}$ versus 800 mg of imatinib mesylate (IM) in patients (pts) with newly diagnosed, previously untreated chronic Myeloid leukemia in chronic phase (CML-CP) using molecular endpoints: 1-year results of TOPS (tyrosine kinase inhibitor optimization and selectivity) study. 50. ASH annual meeting, San Fransisco, CA, December 6-9, 2008: A335.

26. Porkka K, Khoury HJ, Paquette RL, et al. Dasatinib $100 \mathrm{mg}$ once daily minimizes the occurrence of pleural effusion in patients with chronic myeloid leukemia in chronic phase and efficacy is unaffected in patients who develop pleural effusion. Cancer 116: 377-386, 2010.

27. Mustjoki S, Ekblom M, Arstila TP, et al. Clonal expansion of T/NK-cells during tyrosine kinase inhibitor dasatinib therapy. Leukemia 23: 1398-1405, 2009. 
28. Schiffer CA, Cortes JE, Saglio G, et al. Association of lymphocy-tosis following treatment with dasatinib with response and out-come. ASCO annual meeting, Chicago, IL, June 4-8, 2010: A6553.

29. Schiffer CA, Cortes JE, Saglio G, et al. Lymphocytosis following first-line treatment for CML in chronic phase with dasatinib is associated with improved responses: a comparison with imatinib. 52. American Society of Hematology Annual Meeting, Orlando, FL.December 4-7, 2010; A358.

30. Kantarjian H, Pasquini R, Hamerschlak N, et al. Dasatinib or high-dose imatinib for chronic-phase chronic myeloid leukemia after failure of first-line imatinib: a randomized phase 2 trial. Blood 109:5143-5150, 2007.

31. Hochhaus A, Baccarani M, Deininger M, et al. Dasatinib induces durable cytogenetic responses in patients with chronic myelogenous leukemia in chronic phase with resistance or intolerance to imatinib. Leukemia 22: 1200-1206, 2008.

32. Shah NP, Kasap C, Weier C, et al. Transient potent $\mathrm{BCR}-\mathrm{ABL}$ inhibition is sufficient to commit chronic myeloid leukemia cells irreversibly to apoptosis. Cancer Cell 14: 485-493, 2008

33. Saydam G, Haznedaroglu IC, Temiz Y, et al. Retrospective evaluation of patients treated with dasatinib for Philedelphia positive leukemias: Turkish experience of 16 months. UHOD 19: 195-204, 2009

34. Saydam G, Kosova B, Sahin F. Succesful dasatinib treatment in chronic myeloid leukemia after long term imatinib failure: case report. UHOD 20 (suppl 2): 1721, 2010 .
35. Buyukasik Y, Haznedaroglu IC, IIhan O. Chronic myeloid leukemia: Practical issues in diagnosis, treatment and follow-up. UHOD 2: 1-12, 2010.

36. Buyukasik Y. Use of Second Generation Tyrosine Kinase Inhibitors for Second-Line Treatment of Chronic Myeloid Leukemia After Imatinib Failure. UHOD 21 (suppl 2): 4-9, 2011.

37. Haznedaroglu IC, Cetiner M, Ilhan O. The management of chronic myeloid leukemia in the era of second generation tyrosine kinase inhibitors. UHOD 21(2, suppl 2):1-3, 2011.

38. Yavuz AS. Long-term treatment of chronic myeloid leukemia. UHOD 21 (2, suppl 2): 10-17, 2011.

\section{Correspondence}

\section{Dr. Salin AKSU}

Hacettepe Üniversitesi Tıp Fakültesi

Iç Hastalıkları ABD, Hematoloji Ünitesi

Sinhiye, Ankara / TURKEY

Tel: (+90.312) 3051543

Fax: (+90.312) 3051614

e-mail: saksu@hacettepe.edu.tr 